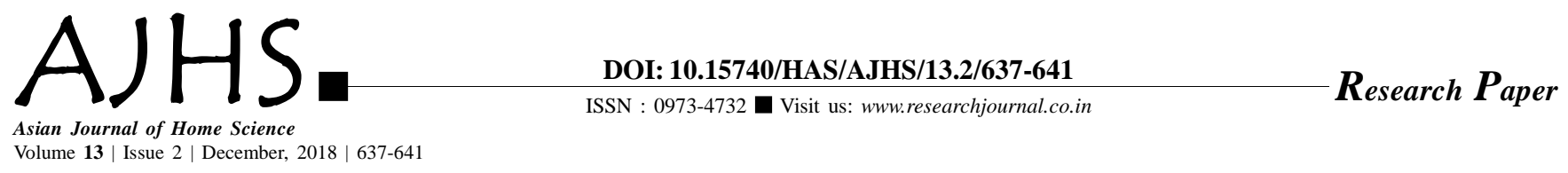

\title{
Home environment and its association with mental development of infants
}

Author for Correspondence :

Shipra Nagar

Department of Human

Development and Family Studies,

Collge of Home Science, Central

Agricultural University, Tura

(Meghalaya) India

Email : shipranagar@gmail.com

Received: 07.06.2018; Revised: 13.11.2018; Accepted: 26.11 .2018

ABSTRACT : The present research aimed at investigating home environment of infants and its association with their mental development. The study was carried out in the villages of two districts of Meghalaya (West and South Garo Hills). A sample of 100 infants from birth to two years was selected randomly from four villages of the districts. Developmental Assessment Scale for Indian Infants (DASII) and a modified HOME inventory developed by Bradley and Caldwell were used for assessing mental development and home environment of infants, respectively. A pretested and modified self structured interview schedule was also used to elicit information regarding home environment and other aspects from the mothers of the infants. Results revealed that majority of the infants had average category of home environment but had low scores in the area of toys and play materials. They did not possess play materials like beads, blocks, puzzles, picture books, etc. in their homes. A strong association existed between home environment and their mental development. Infants performed poorly on the mental scale indicating low mental development.

KEY WORDS: Home environment, Infants, Mental developments

- HOW TO CITE THIS PAPER : Nagar, Shipra (2018). Home environment and its association with mental development of infants. Asian J. Home Sci., 13 (2) : 637-641, DOI: 10.15740/HAS/AJHS/13.2/ 637-641. Copyright@ 2018: Hind Agri-Horticultural Society. 